\title{
Association between iron and folic acid supplementation and birth weight in Ethiopia: systemic review and meta analysis
}

\author{
Andualem Zenebe* ${ }^{*}$, Kaleab Tesfaye Tegegne, Berhanu Bifato and Abiyu Ayalew Assefa
}

\begin{abstract}
Background: Previous studies on iron with folic acid supplementation and low birth weight indicated different findings. The aim of the current systemic review and meta-analysis was to examine the relationship between iron and folic acid supplementation and birth weight in Ethiopia.

Main body: The databases searched were PubMed, Google Scholar, Web of Science and Cochrane Library in January 2021. AZ, KTT and AAA carried out the data extraction and independently assessed the articles for inclusion in the review using risk-of-bias tool guided by PRISMA checklist. The combined Odds ratio with 95\% confidence interval was calculated using random effect model. Twenty four observational studies involving 10,989 participants, 2423 newborns who were born LBW were included. The combined effect size (OR) for low birth weight comparing women who have Iron and Folic acid supplementation versus women who did not have iron and folic acid supplementation was $0.39\left(95 \% \mathrm{Cl} 0.27-0.59, p<0.00001, \mathrm{I}^{2}=91 \%\right)$. There was significant heterogeneity $\left(\mathrm{Q}=264.16, \mathrm{I}^{2}=91 \%, p<0.00001\right)$. No publication bias was observed (Egger's test: $p=0.742$, Begg's test: $p=0.372$ ). Overall $69.5 \%$ of women reported having iron and folic acid supplementation during current pregnancy. And the overall proportion of low birth weight was $22.1 \%$.
\end{abstract}

Conclusions: Women who were supplied with iron and folic acid during pregnancy had a $67 \%$ decreased chance of delivering low birth weight new born in Ethiopia.

Keywords: Determinant of birth weight, Low birth weight, Iron and folic acid supplementation, Meta-analysis, Systematic review, Ethiopia

\section{Background}

Low Birth Weight (LBW) is defined as having a birth weight of less than $2500 \mathrm{~g}$ irrespective of the gestational age of the neonate by World Health Organization (WHO) (UNICEF 2001). It is one of the major global public health problems and is associated with various consequences (WHO 2014).

According to an estimation of United Nations Children's Fund (UNICEF)-WHO, globally one in seven live births (20.5 million babies) suffered from low birth

*Correspondence: anduz143@gmail.com

Department of Public Health, Hawassa College of Health Science, Hawassa, Ethiopia weight in 2015. This report also indicated that data on birth weight were not available for 39.7 million newborns in 2015 worldwide and half of those were from Africa (WHO 2019).

There is disparity on the prevalence of LBW in developing countries. A study which analyzed secondary data of 10 Demographic and Health Surveys (DHS) from developing countries found an overall LBW prevalence of 15.9\% (Mahumud et al. 2017). Studies conducted among Indian and Malaysian women also found $16.5 \%$ and $6.38 \%$ prevalence of LBW respectively (Bharati et al. 2011; Kaur et al. 2019). A cross-sectional study conducted in five African counties found $13.4 \%$ prevalence of LBW in 
Burkina Faso, $10.2 \%$ in Ghana, $12.1 \%$ in Malawi, $15.7 \%$ in Senegal and 10\% in Uganda (He et al. 2018).

Prevalence of LBW in varies across regions in Ethiopia. The 2016 Ethiopian Demographic and Health Survey (DHS) reported 13\% prevalence of small size babies based on the subjective report of the mothers (CSA 2016). Studies conducted in different regions of Ethiopia have shown that prevalence of LBW ranged from 17.5 to $22.5 \%$ in Northwest and Southwest respectively (Demelash et al. 2015; Zeleke et al. 2012).

The two major processes that govern birth weight are duration of gestation and intrauterine growth rate, thus LBW is caused by either a short gestation period or intrauterine growth retardation (or a combination of both factors) (Kramer 1987; WHO 2011, 2019). Some of the factors that are found to be predicators of LBW in one study may not necessarily be a predictor factor in another study. Supporting the argument on possible determinants of LBW vary across the geographical location (Mulatu et al. 2016).

Different studies reported inconsistent results regarding the association between LBW and Iron and Folic acid (IFA) supplementation. A randomized clinical trial (RCT) conducted in rural China for instance found no differences in birth weight or other infant outcomes with iron supplementation (Zhao et al. 2015). On the other hand, according to a RCT conducted in Cleveland, daily iron supplements given to non anemic pregnant women lead to significant reduction in the incidence of infants with LBW (Cogswell et al. 2003). Similarly, previous studies in Ethiopia (Mulatu et al. 2016; Girma et al. 2019; Asmare et al. 2018a; Mehare and Sharew 2020; Gebregzabiherher et al. 2017) have shown a relationship between IFA supplementation and LBW and other studies in Ethiopia have shown absence of association between IFA supplementation and LBW (Teklehaimanot 2014; Alemu et al. 2018; Edris and Erakli 1996; Toru and Anmut 2020; Chanie and Dilie 2018; Gebrehawerya et al. 2018; Baye Mulu et al. 2020; Dilnessa et al. 2018; Dadi 2015).

Nowadays using study result from meta-analysis can provide concrete evidence and have got due attention worldwide (Dadi 2015). No meta-analysis was conducted to show the effect of Iron with folic acid supplementation on low birth weight in Ethiopia. Therefore, the aim of the current meta-analysis was to determine the pooled effect size of association between IFA supplementation and LBW by reviewing evidences from studies conducted in Ethiopia.

\section{Main text Study design}

Meta-analysis of the association between IFA supplementation and birth weight in Ethiopia was done.

\section{Search approach and appraisal of studies}

PubMed, Google Scholar, Web of Science and Cochrane Library were searched in January 2021. We also searched for unpublished works and government documents through Google search. The search for relevant studies to be included in this meta-analysis was conducted by two of the authors independently. EndNote software was used for search of studies from PubMed and Web of science databases. The other articles were searched from Google scholar and Google individually downloaded and manually entered into EndNote. References of studies that meet eligibility criteria were also used to identify similar articles.

Studies were searched using primary key terms of 'determinant of birth weight', 'birth weight', 'iron supplementation, 'iron and folic acid supplementation and birth weight,' 'Ethiopia' and to generate additional keywords for the search we used the following search strategies; "iron and folic acid supplementation + birth weight + Ethiopia"; iron and folic acid supplementation + birth weight through electronic databases on reference manager software.

\section{Inclusion criteria and exclusion criteria}

Available studies and data were included based on the following predefined inclusion criteria. (1) All studies that assessed the relationship between iron with folic acid supplementation and birth weight in Ethiopia, (2) studies which considered LBW outcome of interest (3) studies that reported the percentage of low birth weight according to IFA supplementation and (4) studies that meet quality assessment were included in the study.

On the other hand, Studies that (1) were duplicates, (2) published in languages other than English, (3) studies with birth weight not dichotomized as low and normal and (4) studies with iron with folic acid supplementation not dichotomized as 'Yes' and 'No' were excluded from the study.

\section{Data extraction}

AZ, KTT and AAA carried out the data extraction. The extracted information from eligible studies were the name of the author(s), study design, sample size, study area, the number and percentage of low birth weight and the number and percentage of iron with folic acid supplementation.

\section{Risk of bias and quality assessment}

To assess external and internal validity, a risk-of-bias tool was used. The tool has seven items: (1) random sequence generation (selection bias), (2) allocation concealment (selection bias), (3) blinding of participants (performance 

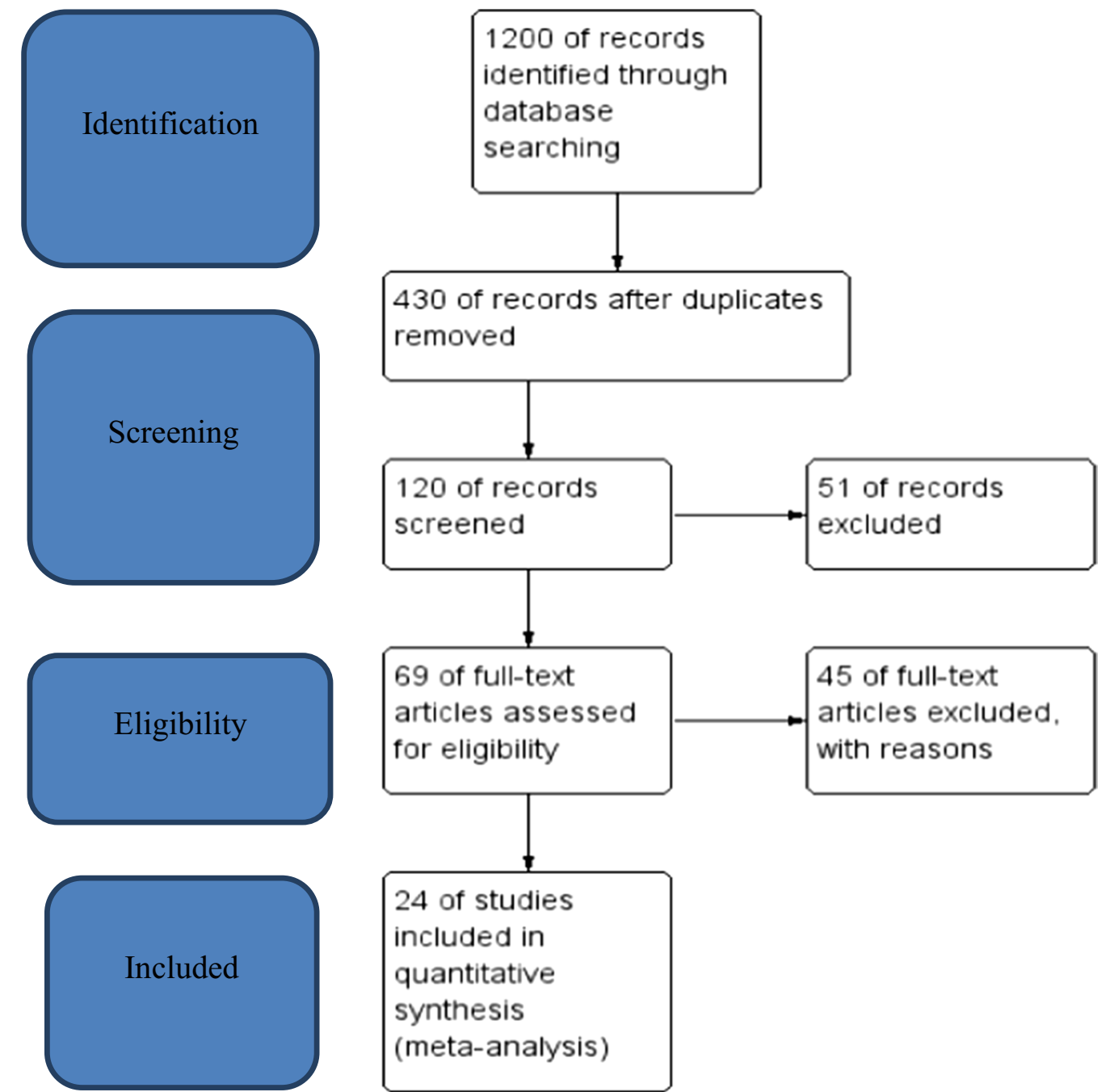

\section{4 of studies included in quantitative synthesis (meta-analysis)}

Fig. 1 PRISMA flow chart of selection process of the included studies

bias), (4) blinding of outcome assessment (detection bias), (5) incomplete outcome data, (6) selective reporting and (7) other bias. All of these items are rated based on the author's subjective judgment given responses to the preceding seven items rated as low, moderate or high risk (Rev 2014).

Three reviewers assessed the articles independently for inclusion in the review using risk-of-bias tool and guided by PRISMA checklist. A discrepancy faced by reviewers on selection of studies and data extraction was resolved by discussion. Additionally, all potential confounding variables were controlled by multivariable analysis in all included studies.

\section{Measures}

Outcome variable Low Birth Weight (LBW) was having a birth weight of less than $2500 \mathrm{~g}$ irrespective of the gestational age of the neonate.

\section{Statistical analysis}

The necessary information was extracted from each original study by using a format prepared in Microsoft Excel spreadsheet and transferred to Meta-essential and Revman software for further analysis. Pooled effect size of LBW was estimated from the reported proportion of eligible studies using RevMan V.5.3 software. Forest plots were generated displaying $\mathrm{MH}$ odd ratio with the corresponding 95\% CIs for each study. As the test statistic showed significant heterogeneity among studies $\left(\mathrm{I}^{2}=90.91 \%, \mathrm{Q}=253.04, p<0.00001\right)$ the random effects model was used to estimate the DerSimonian and Laird's (DL's) pooled effect.

\section{Assessment of heterogeneity}

To examine the magnitude of the variation between studies, heterogeneity was quantified the by using the $\mathrm{I}^{2}$ measure and its $\mathrm{p}$ value. Meta regression was 
Table 1 Characteristics of included studies for association between IFA supplementation and birth weight in Ethiopia, $2020(\mathrm{n}=24)$

\begin{tabular}{|c|c|c|c|c|c|c|c|}
\hline \multirow[t]{2}{*}{ S. no. } & \multirow[t]{2}{*}{ Author(s) and year } & \multirow[t]{2}{*}{ Sample size } & \multirow[t]{2}{*}{ Study design } & \multirow[t]{2}{*}{ Region } & \multirow[t]{2}{*}{ IFA } & \multicolumn{2}{|c|}{ Birth weight } \\
\hline & & & & & & Low & Normal \\
\hline \multirow[t]{2}{*}{1} & Aynie et al. (2020) & 292 & Cross-sectional & Amhara & Yes & 39 & 221 \\
\hline & & & & & No & 15 & 17 \\
\hline \multirow[t]{2}{*}{2} & Liyew et al. (2020) & 1502 & Cross-sectional & National & Yes & 108 & 745 \\
\hline & & & & & No & 90 & 559 \\
\hline \multirow[t]{2}{*}{3} & Desalegn (2015) & 441 & Case-control & Amhara & Yes & 18 & 43 \\
\hline & & & & & No & 129 & 251 \\
\hline \multirow[t]{2}{*}{4} & Mulatu et al. (2017) & 457 & Cross-sectional & AA & Yes & 17 & 258 \\
\hline & & & & & No & 23 & 159 \\
\hline \multirow[t]{2}{*}{5} & Lake and Fite (2019) & 304 & Cross-sectional & SNNP & Yes & 24 & 189 \\
\hline & & & & & No & 24 & 67 \\
\hline \multirow[t]{2}{*}{6} & Toru and Anmut (2020) & 196 & Cross-sectional & SNNP & Yes & 5 & 125 \\
\hline & & & & & No & 12 & 42 \\
\hline \multirow[t]{2}{*}{7} & Chanie and Dilie (2018) & 243 & Cross-sectional & Amhara & Yes & 50 & 163 \\
\hline & & & & & No & 14 & 16 \\
\hline \multirow[t]{2}{*}{8} & Mingude et al. (2020) & 300 & Case-control & SNNP & Yes & 33 & 202 \\
\hline & & & & & No & 27 & 38 \\
\hline \multirow[t]{2}{*}{9} & Asmare et al. (2018b) & 453 & Case-control & Amhara & Yes & 95 & 244 \\
\hline & & & & & No & 48 & 42 \\
\hline \multirow[t]{2}{*}{10} & Gebrehawerya et al. (2018) & 287 & Case-control & Amhara & Yes & 74 & 175 \\
\hline & & & & & No & 22 & 16 \\
\hline \multirow[t]{2}{*}{11} & Girma et al. (2019) & 279 & Case-control & Oromia & Yes & 64 & 166 \\
\hline & & & & & No & 29 & 20 \\
\hline \multirow[t]{2}{*}{12} & Desta et al. (2020) & 381 & Case-control & Tigray & Yes & 112 & 234 \\
\hline & & & & & No & 15 & 20 \\
\hline \multirow[t]{2}{*}{13} & Mulu et al. (2020) & 279 & Case-control & AA & Yes & 65 & 145 \\
\hline & & & & & No & 25 & 35 \\
\hline 14 & Bekela et al. (2020) & 354 & Case-control & Sidama & Yes & 15 & 104 \\
\hline & & & & & No & 90 & 112 \\
\hline 15 & Hailemichael et al. (2020) & 405 & Case-control & Tigray & Yes & 89 & 239 \\
\hline & & & & & No & 46 & 31 \\
\hline 16 & Gizaw and Gebremedhin (2018) & 470 & Case-control & Oromia & Yes & 26 & 159 \\
\hline & & & & & No & 68 & 217 \\
\hline 17 & Jember et al. (2020) & 358 & Cross-sectional & Amhara & Yes & 40 & 261 \\
\hline & & & & & No & 16 & 41 \\
\hline 18 & Siyoum and Melese (2019) & 330 & Case-control & Sidama & Yes & 47 & 169 \\
\hline & & & & & No & 63 & 51 \\
\hline 19 & Gebremeskel et al. (2017) & 420 & Case-control & SNNP & Yes & 144 & 130 \\
\hline & & & & & No & 14 & 131 \\
\hline 20 & Adem et al. (2020) & 464 & Case-control & Tigray & Yes & 82 & 279 \\
\hline & & & & & No & 34 & 51 \\
\hline 21 & Alemu et al. (2018) & 282 & Case-control & SNNP & Yes & 38 & 204 \\
\hline & & & & & No & 19 & 21 \\
\hline 22 & Ekubagewargies et al. (2019) & 240 & Cross-sectional & Amhara & Yes & 20 & 189 \\
\hline & & & & & No & 12 & 19 \\
\hline 23 & Dendir and Dayesa (2017) & 347 & Case-control & $\mathrm{AA}$ & Yes & 205 & 93 \\
\hline & & & & & No & 30 & 19 \\
\hline 24 & Gudeta et al. (2019) & 1980 & Cross-sectional & SNNP & Yes & 64 & 1600 \\
\hline & & & & & No & 84 & 232 \\
\hline
\end{tabular}




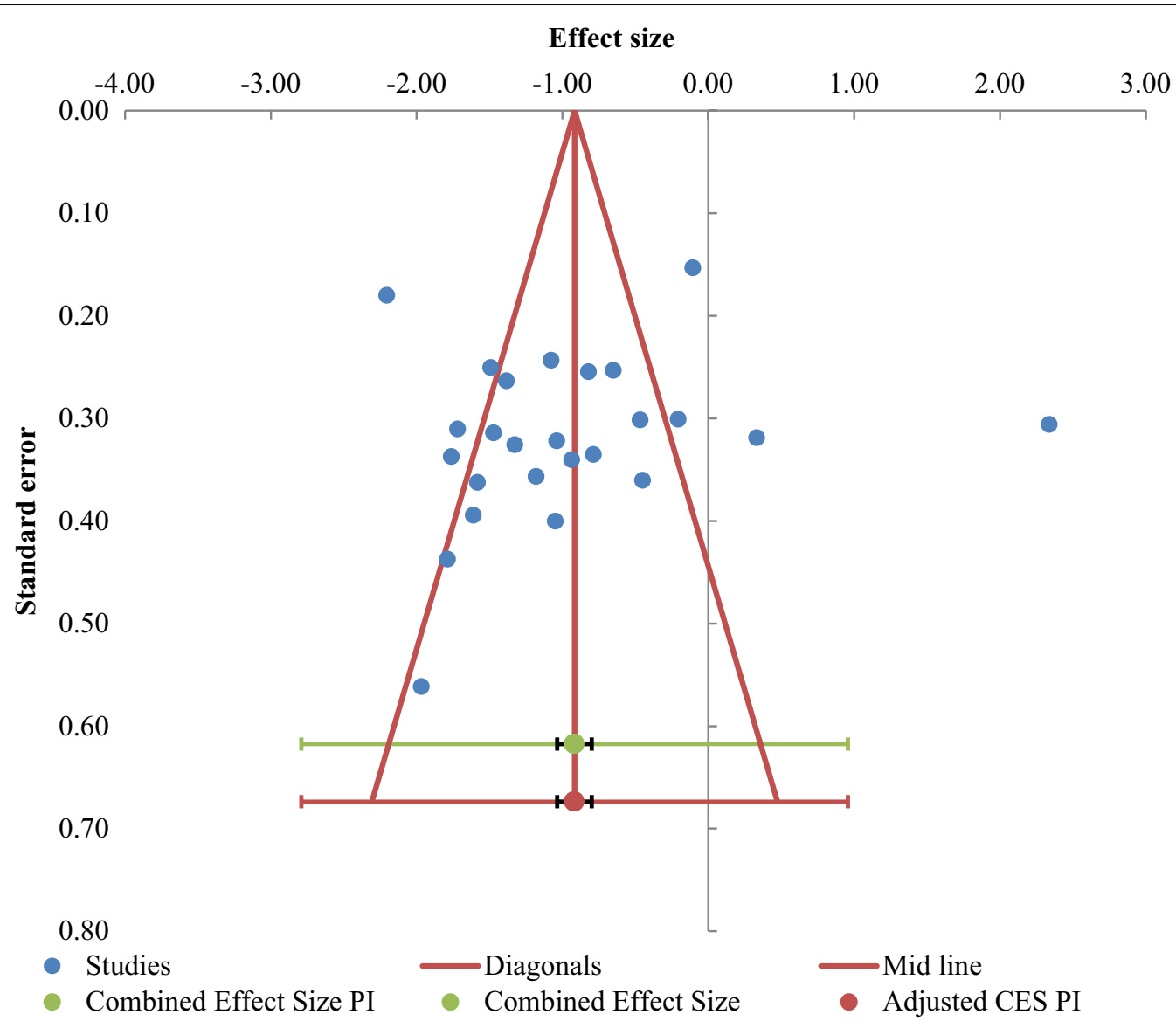

Fig. 2 Funnel plot for IFA supplementation and birth weight in Ethiopia

undertaken by taking low birth weight and iron with folic acid supplementation to identify the potential source of heterogeneity.

\section{Assessment of publication bias}

Funnel plot asymmetry and Egger's test was used to check for publication bias.

\section{Result}

\section{Selected studies}

Figure 1 shows selection process of studies 1200 of records identified through database searching 430 of records after duplicates removed 120 of records screened and 51 of records excluded, 69 of full-text articles assessed for eligibility and 45 of full-text articles excluded, with reasons, studies not in Ethiopia and studies not examining birth weight and iron with folic acid supplementation and finally 24 of studies included in quantitative synthesis (meta-analysis) (Fig. 1).

\section{Characteristics of included studies}

Twenty four (24) studies; 10,967 participants, 2423 newborns who have LBW were included. Table 1 shows description of original studies included $(n=24)$. The studies constitute populations from the different regions of Ethiopia. Three studies from the Tigray region, 7 from Amhara region, 2 studies from the Oromia region, 6 studies from Southern region, 2 studies from Sidama region, 3 studies from Addis Ababa city and one national study were included in the study. Regarding the study design of the included studies; nine were done by cross-sectional study design and fifteen studies by case-control study design (Table 1).

\section{Magnitude of low birth weight}

Overall 7622 (69.5\%) women have taken IFA supplementation during current pregnancy. The overall burden of LBW was $22.1 \%$. The proportion of LBW among women reported IFA supplementation during current pregnancy was $19.34 \%$ and the proportion of LBW among women with no IFA supplementation was $28.37 \%$. 


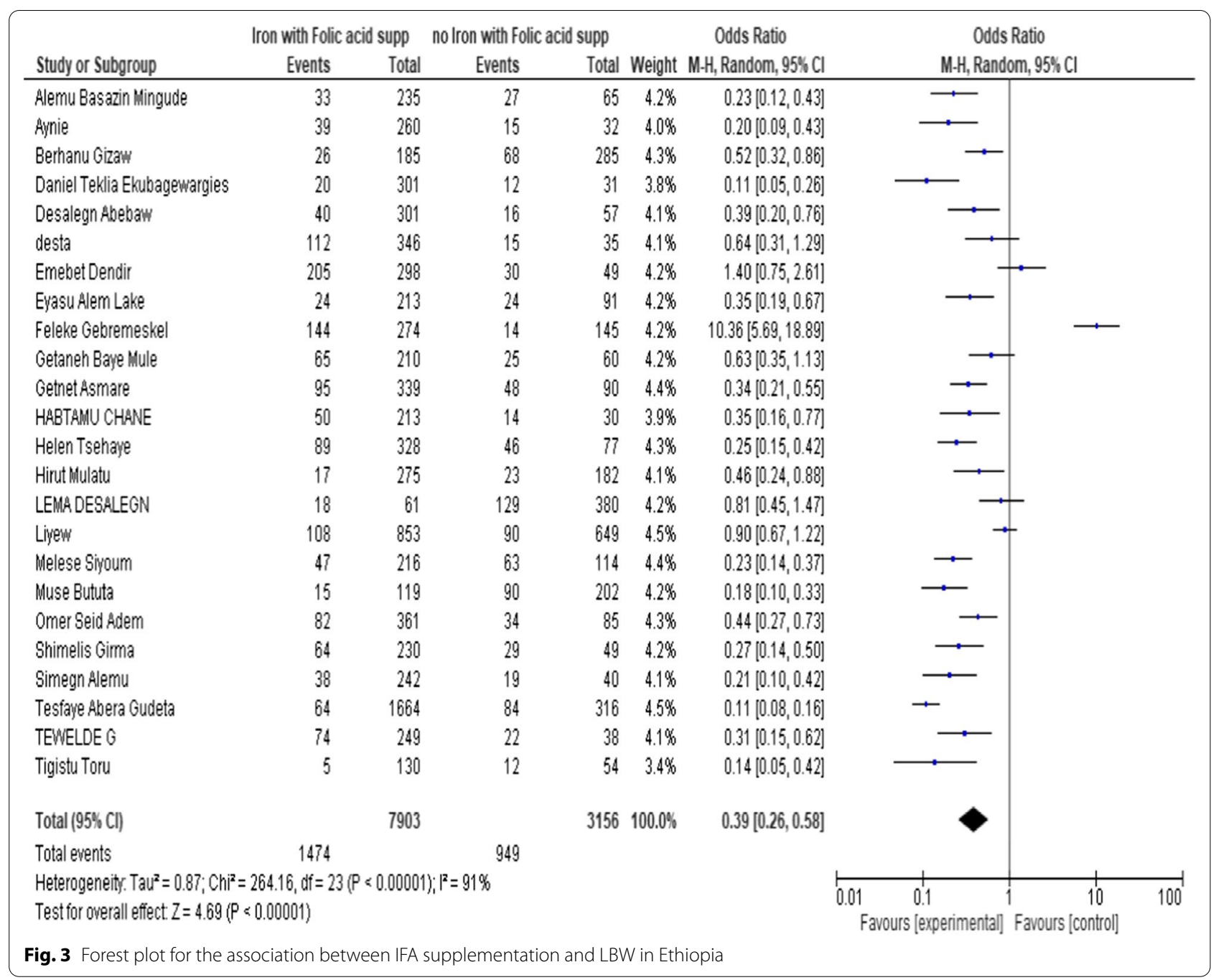

\section{Publication bias and heterogeneity}

The $\mathrm{I}^{2}$ test for heterogeneity showed significant difference among studies $\left.\left(\mathrm{I}^{2}=91 \%, p<0.00001\right)\right)$. No publication bias was observed (Egger's test: $p=0.742$, Begg's test: $p=0.372$ ) (Fig. 2).

\section{Pooled effect size}

The pooled effect size of low birth weight among women with IFA supplementation in the form of odds ratio (OR) was 0.39 (95\% CI $0.27-0.59), p<0.00001 . \mathrm{I}^{2}=90.91 \%$ ) as compared to those without iron/folic acid supplementation (Fig. 3).

\section{Meta regression}

The DerSimonian and Laird random effect model was used to determine the pooled effect size. According to the Meta regression analysis in the random effect model, prevalence of low birth weight and effect size showed significant difference, i.e., the larger the prevalence of low birth weight the larger the effect size would be $(B=0.03$, $p<0.00001$ ) (Fig. 4).

Similarly, as IFA supplementation decreases the odds of low birth weight increases $(B=-0.02, p<0.00001)$ (Fig. 5).

Another sub group analysis was done to see the relationship between LBW and sample size of the studies and the result showed a significant association between LBW and sample size. Accordingly LBW decreases as the sample size of the included studies increases $(B=-0.89$, $p=0.036$ ) (Fig. 6).

\section{Discussion}

In the current meta-analysis, we estimated the pooled effect size of association between IFA supplementation and LBW in Ethiopia. The study showed that the odds of LBW among women with IFA supplementation was decreased by $61 \%(\mathrm{OR}=0.39,95 \%$ CI $0.27-0.59$, 


\section{Regression Analysis}

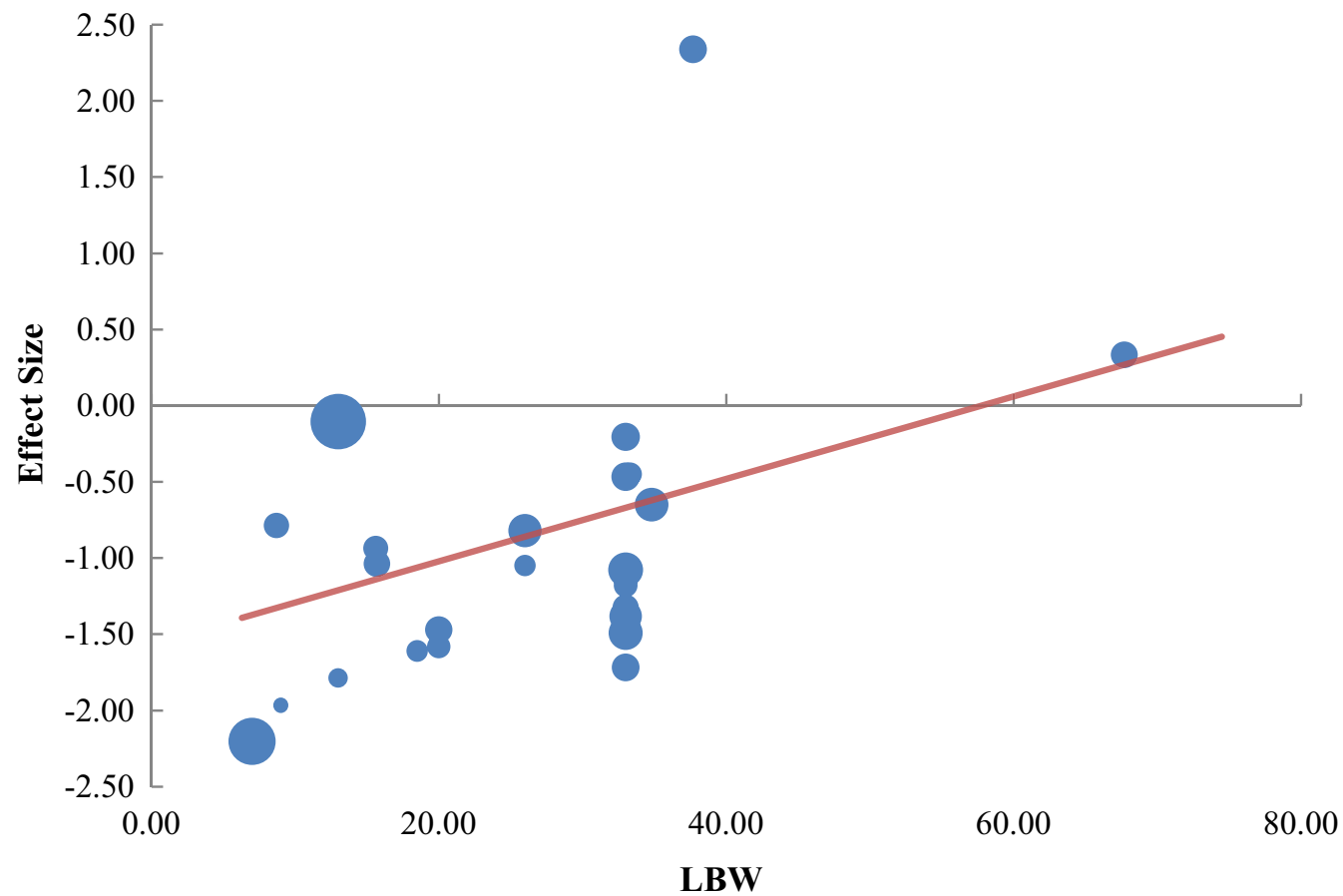

Fig. 4 Prevalence of low birth weight and effect size in Ethiopia

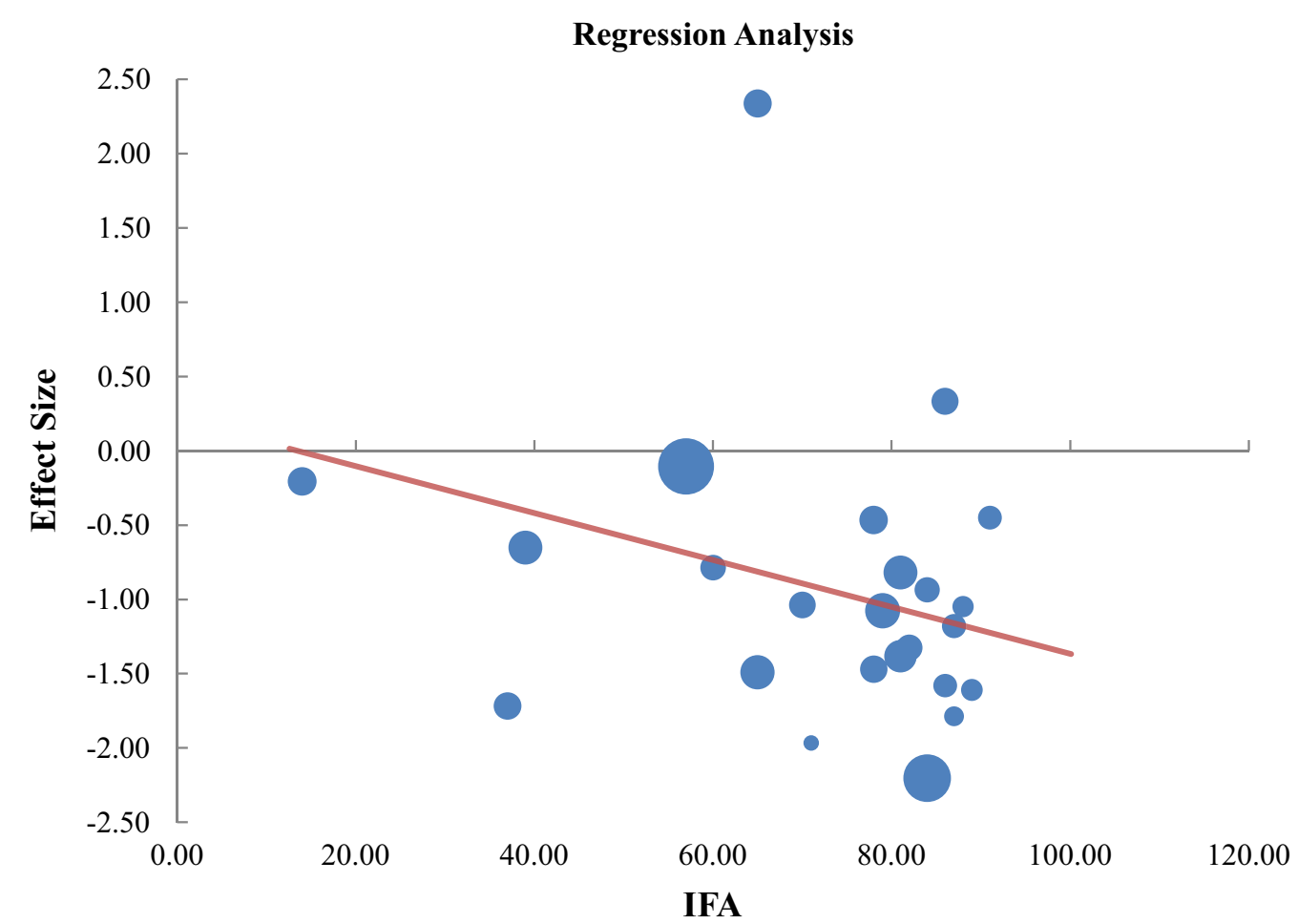

Fig. 5 Iron with folic acid supplementation and effect size in Ethiopia 


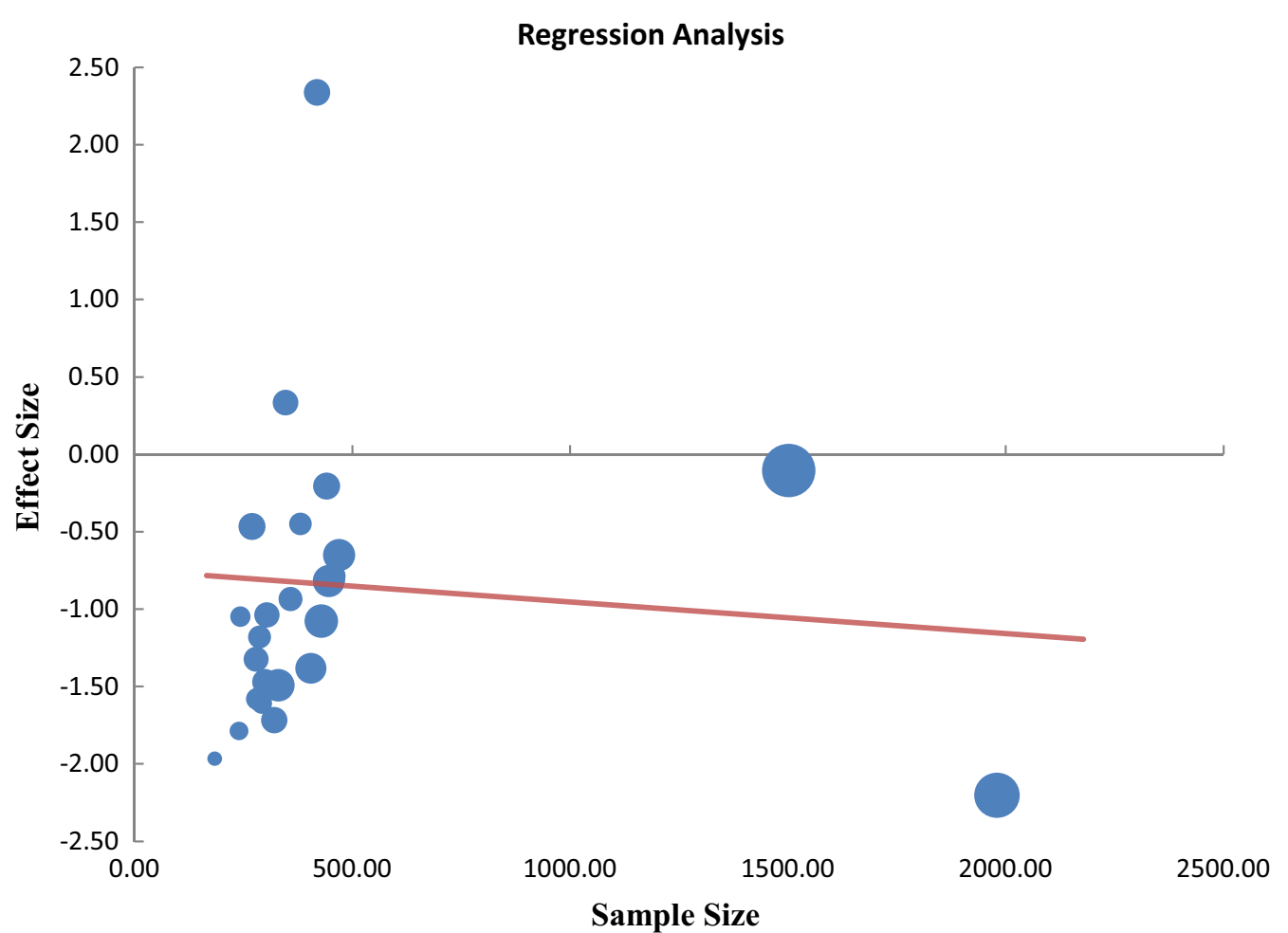

Fig. 6 Sample size and effect size in Ethiopia

$p<0.00001)$ compared to women who have no IFA supplementation. This finding is consistent with previous studies in Ethiopia (Mulatu et al. 2016; Girma et al. 2019; Asmare et al. 2018a; Mehare and Sharew 2020; Gebregzabiherher et al. 2017), Ghana (Zakariah 2016), India (Manna et al. 2013; Ismail and Venugopalan 2016), Bangladesh (Martin et al. 2008), Nepal (Khanal et al. 2006), America (Cogswell et al. 2003) and Mexico (Ramakrishnan et al. 2003).

Even though the mechanism of IFA supplementation on BW is not well understood, there are two hypotheses explaining about improvements in birth weight due to iron supplements (Cogswell et al. 2003). The first hypothesis is that, taking IFA supplementation improves appetite of the mother which leads to improve the overall nutritional status of mothers which sequentially reduces the chance of having LBW newborn. Second, Iron deficiency anemia (IDA) leads to change in norepinephrine, cortisol and corticotrophin which results in oxidative stress to fetal growth leading to having LBW baby which can be reduced by iron supplementation (Cogswell et al. 2003; Allen 2001; Huang et al. 2015).

IFA supplementation for pregnant mothers has a great importance to prevent anemia during pregnancy, thereby enhancing better health outcome for both the mother and the fetus (Kramer 1987; Abu-Ouf and Jan 2015).
Women who were supplemented with iron were less likely to deliver to a LBW baby. This could be due to the fact that, the growing fetus shares nutrients from mother for its intrauterine development.

But it is different from previous studies in Ethiopia (Teklehaimanot 2014; Alemu et al. 2018; Edris and Erakli 1996; Toru and Anmut 2020; Chanie and Dilie 2018; Gebrehawerya et al. 2018; Baye Mulu et al. 2020; Dilnessa et al. 2018) and India (Chiniwar and Menasinkai 2020) which did show any association between iron with folic acid supplementation and low birth weight. The possible explanations for the observed differences of associations between Iron with folic acid supplementation and low birth weight could be the seasonal variations of LBW and differences in sample characteristics, study design, sample size, study time, study area and due to various intervention undertaken between these study time.

The result of this systematic review and meta-analysis should be interpreted in line with its limitations. Firstly, the dataset was not complete due to some restrictions of accessing to full texts. Secondly, due to all of the studies included were done by case-control and crosssectional study design the result might potentially affected by confounding variables and selection bias. The observed high heterogeneity among studies was also considered as limitation of this review. Due to the 
above reasons the investigators recommend longitudinal national studies to assess association between IFA supplementation and LBW.

\section{Conclusion}

Women who take IFA supplementation during pregnancy have a $61 \%$ decreased odds of delivering low birth weight new born in Ethiopia. The prevalence of LBW was higher among women with no IFA supplementation when compared to women who have taken IFA supplementation. Therefore, continued efforts are needed in enhancing universal access to IFA supplementation to improve neonatal health in Ethiopia.

\section{Abbreviations}

AA: Addis Ababa; Cl: Confidence interval; DHS: Demographic and health survey; IFA: Iron and folic acid; LBW: Low birth weight; OR: Odds ratio; UNICEF: United Nations Children's Fund; WHO: World Health Organization.

\section{Acknowledgements}

We would like to thank all the primary authors of the included articles.

\section{Authors' contributions}

$A Z, K T T, B B$ and $A A A$ contributed to the idea of the study and study design. AAA, KTT and BB established the search strategy. AZ, KTT and AAA carried out the data extraction. AZ, KTT, BB and AAA contributed in analysis and interpretation of data and drafting the article for intellectual content. AZ revised the final manuscript, and is the corresponding author. All of the authors read and approved the final manuscript.

\section{Funding}

No funding was received for this meta-analysis.

\section{Availability of data and materials}

All analyzed data are included in the article.

\section{Declarations}

Ethics approval and consent to participate

Not applicable.

\section{Consent for publication}

Not applicable.

\section{Competing interest}

The authors declare that they have no competing interest.

Received: 9 March 2021 Accepted: 17 July 2021

Published online: 23 July 2021

\section{References}

Abu-Ouf NM, Jan MM (2015) The impact of maternal iron deficiency and iron deficiency anemia on child's health. Saudi Med J 36(2):146-149

Adem OS, Gebresalassie NH, Tekele TH (2020) Determinants of low birth weight infants in Mekelle Zone, Tigray region, Northern Ethiopia-casecontrol study

Alemu S, Workicho A, Nigatu M, Bokila T, Wolde T (2018) Determinants of low birth weight in public health facilities, of Kambata Tembaro zone, South Ethiopia. PONS-Medicinski Casopis 15(2):66-74

Allen LH (2001) Biological mechanisms that might underlie iron's effects on fetal growth and preterm birth. J Nutr 131:581S-589S
Asmare G, Berhan N, Berhanu M, Alebel A (2018a) Determinants of low birth weight among neonates born in Amhara Regional State Referral Hospitals of Ethiopia: unmatched case control study. BMC Res Notes 11(1):447

Asmare G, Berhan N, Berhanu M, Alebel A (2018b) Determinants of low birth weight among neonates born in Amhara Regional State Referral Hospitals of Ethiopia: unmatched case control study. BMC Res Notes 11(447):1-7

Aynie AA, Kassa TB, Abie DD (2020) Prevalence of low birth weight and its determinants in Bahir Dar City, Amhara Region, North West Ethiopia: health facility based cross-sectional study. Biomed Stat Inform 5(1):1-8

Baye Mulu G, Gebremichael B, Wondwossen Desta K, Adimasu Kebede M, Asmare Aynalem Y, Bimirew GM (2020) Determinants of low birth weight among newborns delivered in public hospitals in Addis Ababa, Ethiopia: case-control study. Pediatr Health Med Ther 11:119-126

Bekela MB, Shimbre MS, Gebabo TF, Geta MB, Tonga AT, Zeleke EA et al (2020) Determinants of low birth weight among newborns delivered at public hospitals in Sidama Zone, South Ethiopia: unmatched case-control study. J Pregnancy 2020:4675701

Bharati P, Pal M, Bandyopadhyay M, Bhakta A, Chakraborty S (2011) Prevalence and causes of low birth weight in India. Malays J Nutr 17(3):301-313

Central Statistical Agency (CSA) [Ethiopia] and ICF (2016) Ethiopia demographic and health survey 2016. Addis Ababa, Ethiopia, and Rockville, Maryland, USA: CSA and ICF

Chanie H, Dilie A (2018) Prevalence of low birth weight and associated factors among women delivered in debre markos referral hospital, East Gojam, Ethiopia. J Health Med Nurs 53

Chiniwar MA, Menasinkai SB (2020) A study on maternal factors affecting low birth weight in institutional deliveries. Int J Reprod Contracept Obstet Gynecol 9(10):4245-4249

Cogswell ME, Parvanta I, Ickes L, Yip R, Brittenham GM (2003) Iron supplementation during pregnancy, anemia, and birth weight: a randomized controlled trial. Am J Clin Nutr 78:773-781

Dadi AF (2015) A systematic review and meta-analysis of the effect of short birth interval on infant mortality in Ethiopia. PLoS ONE 10(5):e0126759

Demelash H, Motbainor A, Nigatu D, Gashaw K, Melese A (2015) Risk factors for low birth weight in Bale zone hospitals, South-East Ethiopia: a casecontrol study. BMC Pregnancy Childbirth 15:264

Dendir E, Deyessa N (2017) Substance use and birth weight among mothers attending public hospitals: a case control study. Ethiop J Health Dev 31(1):27-35

Desalegn L (2015) Determinants of low birth weight in Debre berehan referal hospital, North Shoa zone, Amhara regional state, Ethiopia (a case-control study). Addis Ababa University

Desta SA, Damte A, Hailu T (2020) Maternal factors associated with low birth weight in public hospitals of Mekelle city, Ethiopia: a case-control study. Ital J Pediatr 46(1):124

Dilnessa T, Belete E, Tefera M (2018) Prevalence of low birth weight and associated factors among new born babies in Ataye Primary Hospital, North Shoa, Ethiopia. Asian J Med Health 2020:1-11

Edris M, Erakli G (1996) The prevalence of low birth weight and factors associated with low birth weight delivery in Gondar Region, north west Ethiopia. Ethiop J Health Dev 10(3):149-152

Ekubagewargies DT, Kassie DG, Takele WW (2019) Maternal HIV infection and preeclampsia increased risk of low birth weight among newborns delivered at University of Gondar specialized referral hospital, Northwest Ethiopia, 2017. Ital J Pediatr 45(1):7

Gebregzabiherher Y, Haftu A, Weldemariam S, Gebrehiwet H (2017) The prevalence and risk factors for low birth weight among term newborns in Adwa General Hospital, Northern Ethiopia. Obstet Gynecol Int 2017:2149156

Gebrehawerya T, Gebreslasie K, Admasu E, Gebremedhin M (2018) Determinants of low birth weight among mothers who gave birth in Debremarkos Referral Hospital, Debremarkos Town, East Gojam, Amhara Region, Ethiopia. Neonatal Pediatr Med 04(01):145

Gebremeskel F, Gultie T, Kejela G, Hailu D, Workneh Y (2017) Determinants of adverse birth outcome among mothers who gave birth at hospitals in Gamo Gofa Zone, Southern Ethiopia: a facility based case control study. Qual Prim Care 25(5):259-266

Girma S, Fikadu T, Agdew E, Haftu D, Gedamu G, Dewana Z et al (2019) Factors associated with low birthweight among newborns delivered at public 
health facilities of Nekemte town, West Ethiopia: a case control study. BMC Pregnancy Childbirth 19(1):220

Gizaw B, Gebremedhin S (2018) Factors associated with low birthweight in North Shewa zone, Central Ethiopia: case-control study. Ital J Pediatr 44(1):76

Gudeta TA, Regassa TM, Gamtesa LC, Lenjebo TL, Mengistu FWK (2019) Magnitude and factors associated with low birth weight among women delivered in public hospitals of Benchmaji, keffa and Sheka zones South west of Ethiopia, 2018. Ethiop J Reprod Health (EJRH) 11(4):7

Hailemichael HT, Debelew GT, Alema HB, Weldu MG, Misgina KH (2020) Determinants of adverse birth outcome in Tigrai region, North Ethiopia: hospital-based case-control study. BMC Pediatr 20(1):10

He Z, Bishwajit G, Yaya S, Cheng Z, Zou D, Zhou Y (2018) Prevalence of low birth weight and its association with maternal body weight status in selected countries in Africa: a cross-sectional study. BMJ Open 8:e020410

Huang L, Purvarshi G, Wang S, Zhong L, Tang H (2015) The influence of irondeficiency anemia during the pregnancy on preterm birth and birth weight in South China. J Food Nutr Res 3(9):570-574

Ismail IM, Venugopalan P (2016) Case-control study on risk factors of low birth weight in a tertiary care hospital, Kerala. Ann Commun Health 4(3):5-12

Jember DA, Menji ZA, Yitayew YA (2020) Low birth weight and associated factors among newborn babies in Health Institutions in Dessie, Amhara. Ethiop J Multidiscip Healthc 13:1839-1848

Kaur S, Ng CM, Badon SE, Jalil RA, Maykanathan D, Yim HS et al (2019) Risk factors for low birth weight among rural and urban Malaysian women. BMC Public Health 19(Suppl 4):539

Khanal V, Zhao Y, Sauer K (2014) Role of antenatal care and iron supplementation during pregnancy in preventing low birth weight in Nepal: comparison of national surveys 2006 and 2011. Archiv Public Health 72(4):139

Kramer MS (1987) Determinants of low birth weight: methodological assessment and meta-analysis. Bull World Health Organ 65(5):663-737

Lake EA, Olana FR (2019) Low birth weight and its associated factors among newborns delivered at Wolaita Sodo University Teaching and Referral Hospital, Southern Ethiopia, 2018. Int J Pediatr 2019:4628301

Liyew AM, Sisay MM, Muche AA (2020) Spatial distribution and factors associated with low birth weight in Ethiopia using data from Ethiopian demographic and health survey 2016: spatial and multilevel analysis

Mahumud RA, Sultana M, Sarker AR (2017) Distribution and determinants of low birth weight in developing countries. J Prev Med Public Health = Yebang Uihakhoe Chi 50(1):18-28

Manna N, Sarkar J, Baur B, Basu G, Bandyopadhyay L (2013) Socio-biological determinants of low birth weight: a community based study from rural field practice area of medical college, Kolkata, West Bengal (India). IOSR J Dent Med Sci 4:33-39

Martin A, Azimul SK, Matiur AKM, Shamianaz S, Shabnam JH, Islam T (2008) Maternal socioeconomic and nutritional determinants of low birth weight. J Dhaka Med Col 17(2):83-87

Mehare T, Sharew Y (2020) Prevalence and associated factors of low birth weight among term newborns in Dilla Town, Southern Ethiopia. Int J Pediatr 2020:8394578
Mingude AB, Gebretsadik W, Misker D, Woldeamanuel GG (2020) Determinants of low birth weight among live birth newborns delivered at public hospitals in Gamo Gofa Zone, South Ethiopia: unmatched case control study. SAGE Open Med 8:2050312120940544

Mulatu H, Zepre K, Betre M, Hailemicael G (2017) Magnitude and factors associated with low birth weight among new born in selected public hospitals of Addis Ababa, Ethiopia, 2016. Glob J Med Res 17(5).

Ramakrishnan U, González-Cossío T, Neufeld LM, Rivera J, Martorel R (2003) Multiple micronutrient supplementation during pregnancy does not lead to greater infant birth size than does iron-only supplementation: a randomized controlled trial in a semirural community in Mexico. Am J Clin Nutr 77:720-725

Rev Man R (2014) The nordic cochrane centre, the cochrane collaboration. Version 5.3 ed2014

Siyoum M, Melese T (2019) Factors associated with low birth weight among babies born at Hawassa University Comprehensive Specialized Hospital, Hawassa, Ethiopia. Ital J Pediatr 45(1):48

Teklehaimanot N (2014) prevalence and factors associated with low birth weight in axum and laelay maichew districts, North Ethiopia: a comparative cross sectional study. Int J Nutr Food Sci 3(6):560

Toru T, Anmut W (2020) Assessment of low birth weight and associated factors among neonates in Butajira General Hospital, South Ethiopia, cross sectional study, 2019. Int J Pediatr 2020:5841963

UNICEF (2001) Low birth weight. United Nations Children's Fund, New York, USA

United Nations Children's Fund (UNICEF), Organization WH, (WHO) (2019) UNICEF-WHO Low birthweight estimates: Levels and trends 2000-2015. Geneva: World Health Organization

WHO (2011) Optimal feeding of low birthweight infants in low-and middleincome countries. World Health Organization, Geneva, Switzerland

WHO (2014) Global nutrition targets 2025: low birth weight policy brief (WHO/ $\mathrm{NMH/NHD/14.5).} \mathrm{World} \mathrm{Health} \mathrm{Organization,} \mathrm{Geneva}$

Zakariah A (2016) Determinants of low birth weight in neonates born in three hospitals in Brong Ahafo Region: University of Ghana

Zeleke BM, Zelalem M, Mohammed N (2012) Incidence and correlates of low birth weight at a referral hospital in Northwest Ethiopia. Pan Afr Med J 12:4

Zhao G, Xu G, Zhou M, Jiang Y, Richards B, Clark KM et al (2015) Prenatal iron supplementation reduces maternal anemia, iron deficiency, and iron deficiency anemia in a randomized clinical trial in rural china, but iron deficiency remains widespread in mothers and neonates. J Nutr 145(8):1916-1923

\section{Publisher's Note}

Springer Nature remains neutral with regard to jurisdictional claims in published maps and institutional affiliations.

\section{Submit your manuscript to a SpringerOpen ${ }^{\odot}$ journal and benefit from:}

- Convenient online submission

- Rigorous peer review

- Open access: articles freely available online

- High visibility within the field

- Retaining the copyright to your article

Submit your next manuscript at $\boldsymbol{\nabla}$ springeropen.com 